\title{
Correction to: Recent advances in the discovery of novel marine natural products and mycosporine-like amino acid UV-absorbing compounds
}

\author{
Nedeljka N. Rosic ${ }^{1,2}$
}

Published online: 22 September 2021

๑) Springer-Verlag GmbH Germany, part of Springer Nature 2021

\section{Correction to: Applied Microbiology and Biotechnology} https://doi.org/10.1007/s00253-021-11467-9

The original version of this article contains a mistake in the table. The text in Table 1 "Mycosporine-glycine" should be replaced with "Hippospongia lachne (sponges)."

Publisher's note Springer Nature remains neutral with regard to jurisdictional claims in published maps and institutional affiliations.

The online version of the original article can be found at https:// doi.org/10.1007/s00253-021-11467-9

Nedeljka N. Rosic

nedeljka.rosic@scu.edu.au

1 Faculty of Health, Southern Cross University, Southern Cross Drive, Gold Coast, QLD 4225, Australia

2 Marine Ecology Research Centre, Southern Cross University, Military Rd, East Lismore, Lismore, NSW 2480, Australia 